\title{
OS TEMPOS DA VIDA
}

\section{POR LUIZ MENNA-BARRETO}

RESUMO O tema do tempo tem atraído bastante atenção no ambiente acadêmico contemporâneo. Apresentarei uma abordagem na qual são associados os conceitos de condicionamento reflexo clássico com a cronobiologia, área na qual a dimensão temporal da matéria viva é explorada. O conceito de antecipação é proposto como elo central dessa associação. Discuto a seguir os níveis de determinação que podem ser propostos a partir da observação de fenômenos temporais nos organismos. Concluo com as noções de desafios e armadilhas temporais que parecem caracterizar fortemente os dilemas humanos num mundo globalizado, conduzindo a diferentes processos de adaptação resultantes desses desafios $e$ armadilhas.
ABSTRACT Time attracts much attention in the contemporary academic universe. In this article I will propose an association between the concepts of classical reflex conditioning and chronobiology, area in which the temporal dimension of living organisms is studied. The concept of anticipation is proposed as the central link of this association. Distinct levels of determination may be explored based on observations of temporal phenomena in organisms. The notions of temporal challenges and traps seem appropriate to describe human dilemmas in a globalized world; such concepts may help the clarification of the different processes of adaptation.
PALAVRAS-CHAVE Cronobiologia

Condicionamento reflexo Antecipação Ritmos Biológicos Ritmos Circadianos
KEY WORDS

Chronobiology

Reflex Condicioning

Anticipation

Biologial Rhythms 


\section{A DIMENSÃO TEMPORAL DA MATÉRIA VIVA - PRESSUPOSTOS MATERIALISTAS}

O conhecimento biológico tem origem, relevância e permanência no contexto sócio-histórico no qual é produzido, articula-se assim com outros aspectos da cultura, o que torna necessária sua leitura nesse contexto. Dessa forma, mudanças nos paradigmas dominantes adquirem sentidos que ultrapassam a lógica interna atribuída aos fenômenos vitais (KUHN, 2003). Evidentemente, essa abordagem crítica não pode pretender eliminar achados e interpretações no acervo do conhecimento biológico, mas pode e deve situar esse acervo nos cenários nos quais foi concebido. Uma questão recorrente no meio científico dedicado a estudos biológicos é a origem dos fenômenos, que se refere a quando e por quem foram identificados e descritos, qual o impacto que causaram no ambiente acadêmico e na cultura em geral, e como se desenvolveram estudos posteriores inspirados nos achados originais. Muitos textos nos remetem à Grécia Antiga como sede das primeiras perguntas sobre os seres vivos e que mais tarde frutificaram na forma do que hoje se entende por conhecimento contemporâneo. Assim é o caso da descrição do movimento das folhas do tamarindo feita por Androstenes de Tassos em 325 a.C., segundo o relato de Schildknecht (1983) que se constituiria no primeiro registro da possível existência de um sistema de temporização atuante em um ser vivo e expresso por oscilações, que hoje denominamos ritmos biológicos. $\mathrm{O}$ registro seguinte sobre o tema dessas oscilações nos seres vivos é do começo do século XVIII , quando um astrônomo francês observou e publicou um relato sobre os movimentos das folhas de uma planta, a sensitiva (Mimosa pudica), acrescido então da novidade de um experimento: a planta foi colocada em um porão, com obscuridade constante e mesmo nessas condições constantes (iluminação) os movimentos das folhas persistiram por alguns dias (DE MAIRAN, 1729). Ainda de acordo com os registros conhecidos, o fenômeno voltou a ser estudado desta vez por um botânico (DE CANDOLLE, 1832) que não só replicou o achado anterior na mesma espécie de planta, como mediu a duração (período) do ciclo de abertura e fechamento das folhas da sensitiva mantida sob claridade constante. Fenômenos semelhantes em animais começaram a ser descritos no início do século XX e logo em seguida vemos estudos em seres humanos. A presença de oscilações regulares no funcionamento de praticamente todos os seres vivos, interpretada como processo de adaptação aos ciclos ambientais (notadamente ao ciclo de iluminação presente na sequência dia/noite), constituiu a base empírica de uma nova área na Biologia, a Cronobiologia[1]. A própria denominação da área, um neologismo criado para caracterizar fenômenos até então pouco conhecidos, contém o tempo (Cronos) e o estudo da vida (Biologia). O crescimento da área está intimamente ligado à hegemonia das abordagens experimentais em Biologia, cuja perspectiva se desloca da constatação e descrição da vida (típicas da História Natural) para a investigação dos mecanismos que a sustentam. Certamente essa virada dá margem a leituras 
mecanicistas e reducionistas dominantes no cenário cultural contemporâneo presentes na Biologia, especialmente no que se refere a conceitos de Biologia da espécie humana. Entretanto, esse mesmo cenário cultural de meados do século $\mathrm{XX}$ está carregado de uma nova tensão que se expressa, por exemplo, no surgimento e afirmação da área dos Estudos Culturais (HALL, 1996).

\section{A ATUALIDADE DA DISCUSSÃO SOBRE O TEMPO}

Cabe refletir se a inflexão crítica representada pelos Estudos Culturais a partir da segunda metade do século XX, de alguma forma afeta a especialização dominante no campo da Biologia e particularmente nessa nova área da Cronobiologia. Creio que sim, e há diversos exemplos de que essa tendência se concretize nas próximas décadas. A interface entre a Cronobiologia e a saúde do trabalhador parece ser um dos exemplos mais evidentes, dada a quantidade de pesquisadores, publicações e eventos acadêmicos de alguma forma envolvidos em questões como a do trabalho noturno ou em turnos alternantes e os prejuízos à saúde associados a organização temporal do trabalho. Existe desde 2001 uma sociedade científica internacional, a Working Time Society [2]. , cujos congressos bianuais são integralmente dedicados a estudos sobre horários de trabalho. Outro exemplo de organização que ilustra a atualidade do debate sobre o tempo numa perspectiva claramente interdisciplinar é a International Society for the Study of Time[3], criada originalmente em 1966 e que publica a revista Kronoscope - a journal for the study of time atualmente em seu volume 14 e que também promove encontros bianuais. Mais recentemente, contribuições de filósofos, sociólogos e psicólogos[4] sobre a dimensão temporal da sociedade, ampliam e aprofundam o debate sobre o tema do tempo e sua fundamental importância no entendimento de nossas amarras. Dessas leituras fica a impressão de que de alguma forma somos levados a refletir sobre o tempo por nos sentirmos pressionados pela falta de tempo, tão fortemente presente na sociedade contemporânea e que no meio acadêmico pode ser sintetizada por diálogos do tipo: "Sei que você publicou um artigo interessante recentemente..." "Sim, de fato, e o que você achou?" "Não tive tempo de ler..."; e a pilha de leituras por fazer cresce cada vez mais... Talvez um pouco paradoxalmente, entendemos nossa falta de tempo e uma agenda lotada como reveladora da nossa importância. De qualquer forma, vivemos sequências mais ou menos regulares de compromissos que, por assim dizer, ordenam nosso cotidiano. Essas sequências representam no nosso pensamento, uma incorporação dos tempos aos quais nos submetemos, aos quais estamos condicionados. 
Ivan Petrovich Pavlov (1849-1936) chefiava um laboratório russo de pesquisa no qual eram estudados os mecanismos de controle da digestão, tendo sido responsável por uma série de brilhantes descobertas que lhe valeram o Premio Nobel em 1904. Sua contribuição mais conhecida é a demonstração do condicionamento reflexo, que passo a descrever.

Pavlov estudava o mecanismo de regulação da secreção salivar em cães sob o efeito de algumas drogas que a potenciavam ou a inibiam. Chamou a atenção do pesquisador o fato de um cão começar a salivar antes de receber o estímulo de comida na boca, o qual costumava provocar a salivação. Bom observador, associou o episódio ao um som de tamancos de um tratador no corredor, ruído que anunciava a chegada da ração dos animais. Pavlov substituiu o som do tamanco por uma campainha, acionada imediatamente antes da oferta de comida, de modo a criar uma sequência que foi repetida algumas vezes: campainha-comida-salivação. Após algumas repetições da associação, apenas o som da campainha foi capaz de provocar salivação no animal e isso perdurou por algum tempo, extinguindo-se depois, dada a ausência do estímulo da comida. Entretanto, bastava uma única associação campainha-comida para que o comportamento se restaurasse e perdurasse novamente por um bom tempo. As expressões "reflexo incondicionado" e "reflexo condicionado" foram então cunhadas para identificar respectivamente, a resposta simples de salivação ao estímulo da comida, e a resposta mais complexa, temporária, de salivação ao som da campainha que tinha sido associado à oferta de comida. É importante ter em mente esse caráter temporário do condicionamento reflexo no cenário da discussão proposta neste ensaio, por duas razões. Em primeiro lugar, o estímulo condicionado (ou condicionante, como alguns preferem chamá-lo) deve obrigatoriamente preceder o estímulo incondicionado, no caso a comida. Em segundo lugar, essa associação não se estabelece de forma permanente. A primeira consideração nos leva a pensar que a ordenação dos estímulos é essencial para o estabelecimento do reflexo condicionado, a campainha, no caso, funcionando com um sinal da chegada iminente da comida. $\mathrm{O}$ valor do sinal condicionado consiste assim no seu significado de antecipação e é justamente esse valor que confere funcionalidade ao fenômeno do condicionamento reflexo (ANOKHIN, 1974). Quando a ordem de apresentação dos estímulos é invertida, primeiro a comida e depois a campainha, o condicionamento simplesmente não ocorre, daí a inferência a respeito da natureza essencialmente temporal (sequencial) do processo de condicionamento. O caráter temporário do condicionamento reflexo é demonstrado através da repetição do estímulo condicionado (campainha) sem ser seguido da oferta de comida, tende a atenuar e depois extinguir o reflexo. A extinção de um condicionamento pode ser considerada tão importante quanto a aquisição, pois envolve a possibilidade de serem estabelecidas novas associações, como seria o caso de trocarmos a campainha por um outro sinal, um pulso de luz, por exemplo. Essa capacidade de mudança de comportamentos envolve alterações na circuitaria neural envolvida, fenômeno hoje amplamente reconhecido e estudado como plasticidade, propriedade que também valeu em 2000 o Prêmio Nobel em Medicina e Fisiologia[5], décadas depois da honraria conferida a Pavlov em 1904. 


\section{A ASSOCIAÇÃO NECESSÁRIA}

Creio ser adequada a leitura segundo a qual os conceitos de condicionamento reflexo e plasticidade neural, por um lado, e aqueles ligados à Cronobiologia, por outro, evoluíram por caminhos paralelos ao longo do século XX e que talvez tenha chegado o momento de propor suas convergências. Essa convergência dá sentido a uma lacuna importante no campo da Cronobiologia em torno do processo ao longo da evolução que resultou na presença e atuação de sistemas de temporização na matéria viva. Seres vivos que se diferenciaram em espécies diurnas ou noturnas, por exemplo, evidenciam que as oscilações de luminosidade/obscuridade do dia/noite, foram por assim dizer "incorporadas" na organização daqueles seres. Essa incorporação se infere hoje através de demonstrações da persistência de oscilações como o ciclo ou ritmo vigília/sono em humanos em situações nos quais a luminosidade é mantida constante. Nessas condições constantes, o ritmo tende a se expressar em humanos com uma periodicidade que é próxima ao ciclo ambiental do dia/noite, mas não igual, correspondendo nesse exemplo a um ciclo cujo período é de aproximadamente 25h (ASCHOFF; WEVER, 1976). Ritmos observados em condições de isolamento temporal, ou seja, sem sinais externos marcadores de tempo são chamados de ritmos em livre-curso. E é justamente a constatação desses ritmos o argumento principal para propor o controle endógeno da ritmicidade. Os mecanismos responsáveis por essa expressão rítmica acabaram sendo identificados como "relógios biológicos" - denominação bastante inadequada, pois relógios devem ser bastante regulares, do contrário não são relógios. Ora, esses mecanismos, mais adequadamente denominados sistemas de temporização, promovem oscilações nem sempre regulares. Um exemplo é o nosso ciclo vigília/sono, que embora se constitua claramente em um ciclo que se repete aproximadamente a cada 24h, não promove o sono nem o despertar necessariamente nos mesmos horários, como seria se fosse um "bom" relógio[6]. Ritmos em livre-curso vêm sendo demonstrados em praticamente todas as espécies, de protozoários a mamíferos incluindo humanos, sustentando a hipótese do caráter endógeno dos sistemas de temporização.

A hipótese que estamos propondo neste ensaio é justamente a da incorporação de sinais temporais do ambiente ao longo da evolução, quando sinais relevantes para a sobrevivência das espécies constituíram elementos fundamentais para a sua sobrevivência. Desse modo, encontramos hoje espécies cuja atividade se concentra no dia e outras com atividades noturnas, mas em ambos os casos a relação determinante é com o ciclo claro/escuro do dia e da noite. Outras espécies dependem de outros ciclos, como é o caso de caranguejos da orla marinha, para os quais os sinais relevantes são as oscilações da maré. Muitas espécies apresentam combinações de ritmos diários com ritmos anuais, como é o caso da sazonalidade da reprodução em mamíferos. Em todos esses casos estamos autorizados a propor que os sinais temporais do ambiente foram incorporados aos organismos ao longo de sua evolução. Darwin mostrou que o processo de especiação toma rumos distintos conforme o nicho espacial ocupado pelos ancestrais; há que se pensar agora que a ocupação de nichos temporais distintos também acaba determinando possibilidades de sobrevivência e processos de adaptação. Tanto o isolamento 
espacial (Cf. Galápagos aos olhos de Darwin) como o temporal (ocupação com atividades diurnas ou noturnas) atuam como agentes da evolução e é nesse contexto que a história de como os seres vivos contemporâneos chegaram ao seu estado atual deve ser compreendida.

\section{IMPLICAÇÕES CULTURAIS}

O cotidiano humano, notadamente o urbano atual, dificilmente pode ser bem compreendido sem levarmos em consideração a diversidade temporal à qual estamos submetidos. Tanto aqueles tempos do dia e da noite e estações do ano, como tempos marcadamente sociais como a semana ou as férias, condicionam nossos comportamentos. Esse condicionamento evidentemente, não é homogêneo entre as pessoas; enquanto alguns ajustam suas rotinas de forma razoavelmente suave, outros vivem em permanentes conflitos temporais. Nossos hábitos de sono podem ser vistos com a "ponta do iceberg" das tensões entre nossos corpos (e seus sistemas de temporização) e os horários sociais como aqueles da escola ou do trabalho. Essas tensões têm reconhecidamente efeitos sobre a nossa saúde, atingindo em maior ou menor grau outros sistemas orgânicos, por exemplo, nossas defesas imunológicas.

A expressão desafios temporais sintetiza esse conjunto de tensões e hoje sabemos que esses desafios são mais danosos quando são crônicos. Um trabalhador noturno, por exemplo, que vive o que pode ser lido como desafio temporal crônico, dificilmente se adapta aos horários de trabalho e distúrbios de sono e do metabolismo (obesidade) são comuns nessas pessoas (BIRTH, 2007). Paradoxalmente, mudanças de rotina (noites sem sono de festa ou estudo) de curta duração, não acarretam as mesmas consequências, talvez pelo fato de não comprometerem de forma crônica os sistemas de temporização. Igualmente importante me parece também o grau de liberdade que temos ou que gostaríamos de ter na definição dos nossos horários de trabalho/lazer (ou atividade/repouso, num sentido mais amplo). As regras desse jogo passam necessariamente pelos interesses sociais e respectivas hierarquias, constituindo-se numa das expressões mais evidentes das desigualdades sociais contemporâneas. Cabe neste momento uma breve menção às armadilhas temporais nas quais estamos sempre caindo, seja na condição de vítimas, seja na condição de criadores. Em qualquer um dos dois casos cabe identificar tanto o que nos proporciona bem-estar, bem como os possíveis sinais de desconforto e eventual sofrimento embutidos nesses cenários temporais. Temos de aprender a ler os tempos contidos na nossa existência, tanto os que nos são impostos como aqueles que construímos.

\section{notas de rodapé}


1960.

[2]Disponível em: < http://www.workingtime.org/history $>$.

[3]Disponível em: < http://www.studyoftime.org $>$.

[4] Duas obras de autores contemporâneos podem ser citadas como exemplos de reflexões sobre a organização temporal da sociedade, Hartmut Rosa (Social acceleration: a new theory of modernity. Columbia University Press, 2013) e Robert Levine (Geography of time: on tempo, culture and the pace of life. Basic Books, 2008)

[5]Em 2000, Eric Kandel recebeu o Prêmio Nobel em Medicina e Fisiologia em reconhecimento à sua contribuição sobre os mecanismos neurais envolvidos na aprendizagem e memória. O texto de sua conferência na ocasião pode ser lido em: .

[6]Sobre a expressão "relógio biológico", sugiro leitura do texto na página: . Ver também MENNABARRETO, L. Relógio biológico: prazo de validade esgotado. Neurociências, São Paulo, v.2, n.4, p. 14, 2005.

\section{bibliografia}

ANOKHIN, P. K. Biological roots of the conditioned reflex and its role in adaptive behavior. Oxford: Pergamon Press, 1974.

ASCHOFF, J.; WEVER, R. Human circadian rhyhtms: a multioscillatory system. Federation Proceedings, Betheseda, v. 35, n. 14 , p. 2326-2332, Dec. 1976.

BIRTH, K. Time and the biological consequences of globalization. Current Anthropology, Merced, v.48 , n.2, p. 215-236, April 2007.

COLD SPRING HARBOR SYMPOSIA ON QUANTITATIVE BIOLOGY, V. XXV "Biological Clocks", The Biological Laboratory, Cold Spring Harbor, New York, 1960.

DE CANDOLLE, A. Physiologie végétale. Paris: Becket Jeune, 1832. v.2.

DE MAIRAN, J. Observation botanique. In: Histoire de l'Academie Royale des Sciences, 1729. p. 35-36.

HALL, S. Critical dialogues in cultural studies. London: Routledge, 1966.

KUHN, T.S. Estrutura das revoluções científicas. 8. ed. São Paulo: Editora Perspectiva, 2003. (Coleção Debates, 115).

SCHILDKNECHT, H. Tugorins, hormones of the endogenous daily rhyhtms of higher organized plants - detection, isolation structure, synthesis, and activity. Angew. Chem. Int. Ed., England, n. 22, p. 695-710, 1983. 